\title{
Identifying a missing lineage driver in a subset of lung neuroendocrine tumors
}

\author{
Karine Pozo, ${ }^{1,2}$ John D. Minna, ${ }^{3,4,5,6}$ and Jane E. Johnson ${ }^{1,4,5}$ \\ ${ }^{1}$ Department of Neuroscience, ${ }^{2}$ Department of Surgery, ${ }^{3}$ Hamon Center for Therapeutic Oncology Research, ${ }^{4}$ Simmons \\ Comprehensive Cancer Center, ${ }^{5}$ Department of Pharmacology, ${ }^{6}$ Department of Internal Medicine, University of Texas \\ Southwestern Medical Center, Dallas, Texas 75390, USA
}

\begin{abstract}
Tumor heterogeneity of a primary histologic cancer type has major implications for cancer research and therapeutics. An important and understudied aspect of this heterogeneity is the role of transcription factors that serve as "lineage oncogenes" in a tumor type. A demonstration that different subgroups have distinct dependencies on lineage-specific transcription factors is highlighted in a relatively homogenous cancer type: the pulmonary neuroendocrine cancer small cell lung carcinoma (SCLC). Identification of these factors is providing new insights into the origin of the heterogeneity and subtype-specific vulnerabilities in SCLC and provides a template for studying heterogeneity in other cancer types.
\end{abstract}

Heterogeneity across tumors of a given cancer type and the resulting implications for cancer treatment have emerged as major issues in cancer research and therapeutics. A good example is small cell lung carcinoma (SCLC), an aggressive, highly metastatic neuroendocrine cancer of the lung that occurs in smokers, with a 5-yr survival rate of $<7 \%$. There has been little change in SCLC treatment over the past $30 \mathrm{yr}$, causing the National Cancer Institute to categorize it as a "recalcitrant" cancer. Nearly all SCLC patients respond well to initial platinum-etoposide-based chemotherapy (with or without radiotherapy to the primary tumor), but relapse is inevitable (usually occurring within $1 \mathrm{yr}$ ), and recurrent tumors are nearly always resistant to additional treatments. Searching for new targets and drugs from comprehensive genome sequencing, drug screens of preclinical human SCLC models, tests in genetically engineered mouse models (GEMMs) of SCLC, and related efforts to develop rationales and targeted therapies have had limited success, with only small numbers of patients responsive to treatments in clinical trials (Gazdar et al. 2017). A clinical diagnosis of SCLC is usually made in a clinical setting by histologic examination and immunohistochemical detection of neuroendocrine markers.

[Keywords: POU2F3; small cell lung cancer; tuft cell; master regulator; enhancer]

Corresponding author: jane.johnson@utsouthwestern.edu

Article is online at http://www.genesdev.org/cgi/doi/10.1101/gad.316943. 118 .
When molecular analyses are done, in essentially all cases, inactivation of RB1 and TP53 tumor suppressor genes is found (George et al. 2015). However, "variant" forms of SCLC (compared with the majority, which has "classic" features) have been recognized for many years and account for $\sim 10 \%-20 \%$ of all cases. These present clinically like SCLC and have RB1 and TP53 mutations, but, histologically, the cells are larger and lack many neuroendocrine markers found in the usual SCLCs (Gazdar et al. 2017). In human SCLCs, these "variant" types were often found to have amplified and/or express high levels of MYC, and, recently, a GEMM of SCLC that expresses high levels of MYC was also identified to have morphology of the "variant" type (Mollaoglu et al. 2017). Nevertheless, even with the recognized variations in histology, SCLC cell culture characteristics, and neuroendocrine gene signatures, only a single morphological form of SCLC is recognized by the World Health Organization classification in current clinical practice.

Distinguishing SCLC subtypes by expression of neuroendocrine genes such as CHGA and GRP identifies two groups: neuroendocrine high (NE ${ }^{\text {high }} ; \sim 80 \%$ ) and neuroendocrine low ( $\mathrm{NE}^{\text {low }} ; \sim 20 \%$ ). Within the $\mathrm{NE}^{\text {high }}$ group, the basic helix-loop-helix (bHLH) transcription factor ASCL1 is considered a master regulator for a majority of these SCLC, while a related bHLH factor, NEUROD1, characterizes a smaller subset with intermediate neuroendocrine characteristics (Osborne et al. 2013; George et al. 2015; Borromeo et al. 2016; Zhang et al. 2018). In contrast, most NE ${ }^{\text {low }}$ SCLCs do not express ASCL1 or NEUROD1. Thus, ASCL1 and NEUROD1 expression or lack of expression has been used to subdivide SCLCs into ASCL1 ${ }^{\text {high }}$, NEUROD1 $1^{\text {high }}$, or dual-negative SCLC subtypes. ASCL1 and NEUROD1 drive different gene expression programs (Borromeo et al. 2016; Mollaoglu et al. 2017), which may influence individual patient drug responses. Thus, appreciation of the heterogeneity of SCLC tumor subtypes is

(C) 2018 Pozo et al. This article is distributed exclusively by Cold Spring Harbor Laboratory Press for the first six months after the full-issue publication date (see http://genesdev.cshlp.org/site/misc/terms.xhtml). After six months, it is available under a Creative Commons License (Attribution-NonCommercial 4.0 International), as described at http://creativecommons.org/licenses/by-nc/4.0/. 
driving efforts to identify subtype-specific vulnerabilities and define subtype-specific markers to select patient populations for clinical trials.

While ASCL1 and NEUROD1 are lineage-specific transcription factors for the NE ${ }^{\text {high }}$ group of SCLCs, identification of a lineage-specific transcription factor for the $\mathrm{NE}^{\text {low }}$ has been lacking. This deficiency is addressed in this issue of Genes \& Development, where Huang et al. (2018) report the identification of POU2F3 as a master regulator of the NE ${ }^{\text {low }}$ SCLC subtype, demonstrating a dependence on POU2F3 for proliferation and survival. Of great interest relating to neuronal differentiation, they report the unexpected and novel finding that POU2F3 and its downstream transcriptional targets in SCLC share molecular features of rare chemosensory cells in the lung ("tuft" cells), implicating a distinct cell of origin for these $\mathrm{NE}^{\text {low }}$ relative to the $\mathrm{NE}^{\text {high }}$ SCLC (Fig. 1). Furthermore, highlighting the potential therapeutic importance of recognizing heterogeneity in this class of tumors, a subtype-specific vulnerability is found that involves the IGF1R signaling pathway. These findings have translational as well as biological implications for SCLC.

Huang et al. (2018) used a domain-focused CRISPR screen to identify novel transcription factor dependencies in SCLC. Interrogating 1427 DNA-binding domains of human transcription factors in a panel of SCLC cell lines, the investigators identified POU2F3 as essential for NE $\mathrm{NE}^{\text {low }}$ SCLC cell growth. POU2F3, a POU homeodomain transcription factor (also known as SKN-1A), is required for the generation of TRPM5-expressing chemosensory tuft cells in multiple tissues, including the trachea, auditory tube, urethra, thymus, pancreatic duct, stomach, and large intestine (Yamashita et al. 2017). POU2F3 has not been linked to lung cancer, and, until now, the existence of POU2F3-expressing chemosensory cells in the primary and secondary bronchi, where SCLC tumors are found, had not been demonstrated. In the present study, rare POU2F3-expressing cells are found that do not colabel with markers of the CGRP-expressing neuroendocrine cells or other lung epithelial cells, including ciliated and club cells, revealing a possible distinct cell of origin for a subset of SCLC. Strikingly, POU2F3 is expressed in the subset of SCLC tumors $(12 \%-20 \%)$ that lack ASCL1, NEUROD1, and other neuroendocrine lineage markers, including INSM1, CHGA, GRP, and CALCA. Although POU2F3-expressing SCLCs (POU2F3 ${ }^{\text {high }}$ ) display the typical SCLC morphology (originally called "oat cells" by pathologists, thus explaining why they were clinically diagnosed as SCLCs), they are associated with the NE ${ }^{\text {low }}$ SCLC subtype markers REST and MYC as well as chemosensory tuft cells markers, including TRPM5, SOX9, $\mathrm{CHAT}$, and ASCL2. Furthermore, POU2F3 ${ }^{\text {high }}$ cells distinguish themselves from ASCL1 $1^{\text {high }}$ and NEUROD1 $1^{\text {high }}$ SCLC cells at the epigenetic level. Indeed, enhancers of chemosensory tuft cell genes are specifically marked by the active chromatin mark H3K27ac in POU2F3 ${ }^{\text {high }}$, but not in ASCL1 ${ }^{\text {high }}$ or NEUROD1 ${ }^{\text {high }}$, SCLC cells. Thus, the current work in the context of recent enhancer landscape studies shows that all three subgroups-ASCL $1^{\text {high }}$, NEUROD $1^{\text {high }}$, and POU2F3 ${ }^{\text {high }}$ SCLC-are dramatically
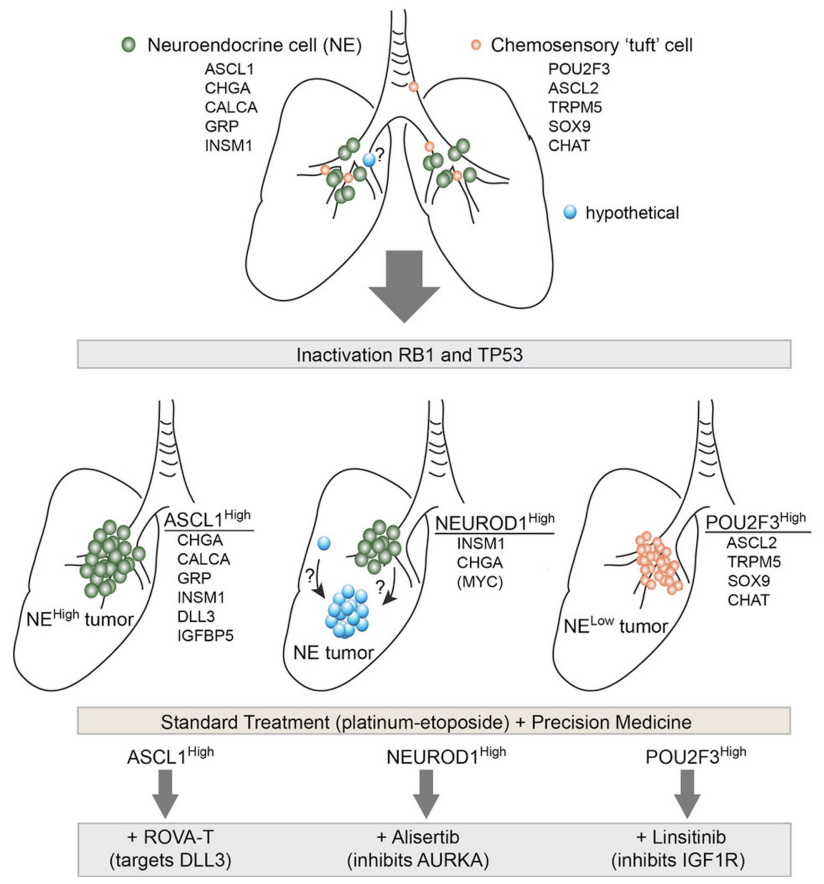

Figure 1. Heterogeneity in SCLC suggests distinct cells of origin, vulnerabilities, and responses to treatment. At least three subtypes of SCLC can be distinguished, including ASCL1 ${ }^{\text {high }}$, NEUROD $1^{\text {high }}$, and POU2F3 $3^{\text {high }}$, with signatures for neuroendo-' crine gene expression going from high to low, respectively. This heterogeneity may result from genetic inactivation of the tumor suppressors RB1 and TP53 in distinct cells in the lung, as just reported (Huang et al. 2018). Rare neuroendocrine and chemosensory cells are found in the bronchial epithelium in the adult lung that share dependency on ASCL1 (neuroendocrine cells; ASCL1 $1^{\text {high }}$ tumors) or POU2F3 (chemosensory tuft cells; POU2F3 $3^{\text {high }}$ tumors). It is not clear whether the NEUROD1 ${ }^{\text {high }}$ SCLCs arise from yet a different cell lineage or whether they reflect an ASCL1 ${ }^{\text {high }}$ tumor that has acquired additional genetic alterations such as MYC amplification. Nevertheless, the distinct chromatin landscape and gene expression seen in these different SCLC subtypes suggest that they will have distinct vulnerabilities and should inform precision medicine strategies (Saunders et al. 2015; Mollaoglu et al. 2017; Huang et al. 2018).

different in their enhancer landscapes and related gene expression profiles, supporting distinct classifications for these tumor subgroups. In the case of the POU2F 3 high subtype, a distinct cell of origin is strongly implicated by Huang et al. (2018). Whether ASCL1 ${ }^{\text {high }}$ and NEUROD $1^{\text {high }}$ SCLC subtypes have cells of origin distinct from each other and the POU2F $3^{\text {high }}$ subtype remains to be determined.

Of great translational importance, Huang et al. (2018) also reasoned that the POU2F3 $3^{\text {high }}$ subgroup of SCLC may use signaling pathways distinct from those used by the NE ${ }^{\text {high }}$ SCLC and that these pathways could provide novel molecular therapeutic targets. To delineate these pathways, they conducted another protein domain CRISPR dropout screen, this time by targeting guides to kinase domains. IGF1R emerged as essential for growth 
of the POU2F3 $3^{\text {high }}$ cell lines. Consistently, POU2F3 ${ }^{\text {high }}$ cells are significantly more sensitive to an IGF1R inhibitor, linsitinib. It is interesting to note that POU2F3 ${ }^{\text {high }}$ SCLC expresses low levels of the endogenous IGF1R inhibitor IGFBP5, whereas ASCL1 ${ }^{\text {high }}$ expresses high levels of IGFBP5 (thus already being in an IGF1R "inhibited" state), possibly accounting for these differences in sensitivity to the IGF1R pathway inhibitor. Together, these findings suggest that patients harboring POU2F $3{ }^{\text {high }}$, but not ASCL1 ${ }^{\text {high }}$, SCLC tumors may be responsive to IGF1R inhibitors. A recent clinical trial with linsitinib of relapsed SCLC failed to show activity (in 29 patients) compared with topotecan (a traditional chemotherapy used after platinum-etoposide) (Chiappori et al. 2016). The report by Huang et al. (2018) now provides a biomarker-based guideline (POU2F3 ${ }^{\text {high }}$ ) for selecting SCLC patients for a follow-up linsitinib trial. As a prelude to the clinical trial, it will be crucial to determine whether the POU2F3 ${ }^{\text {high }}$ subtype of SCLC will show a dramatic response to linsitinib in a xenograft model in vivo.

There are multiple direct implications from the study by Huang et al. (2018) that impact our understanding of the heterogeneity in SCLC and should inform the design of future clinical trials. POU2F3 as a lineage driver of the NE ${ }^{\text {low }}$, ASCL $1^{\text {low }}$, and NEUROD $1^{\text {low }}$ SCLC subtypes and the identification of rare POU2F3-expressing chemosensory tuft cells in the normal bronchial epithelium strongly suggest a previously unrecognized cell of origin for a subset of SCLC. However, it is also possible that the different SCLC subtypes may transition from one type to the other. This may be the case between ASCL1 ${ }^{\text {high }}$ and NEUROD1 ${ }^{\text {high }}$ subtypes and even possibly in the case of non-small cell lung cancers with EGFR mutations transitioning with EGFR targeted therapy to resistance, occasionally expressing SCLC morphology and features (Niederst et al. 2015). Future experiments are required to formally test and distinguish between these models. A second implication supported by the Huang et al. (2018) report is that the POU2F3 ${ }^{\text {high }}$ subtype may have specific vulnerabilities, such as via IGF1R signaling, and any further preclinical and clinical studies in this area should stratify models/patients in order to not miss significant responses to treatments in this minority subset of SCLC. Finally, for ASCL1-, NEUROD1-, and POU2F3-driven cancers, can they become resistant to these lineage dependencies (e.g., by switching from one transcription factor dependency to another)? These studies continue to raise awareness that there may be other, sometimes rare, cell types that can serve as originating cells for tumors and, when combined with oncogenic genetic alterations, provide heterogeneity in histologically similar cancers. Incorporating this knowledge into the design of drug screens and clinical trials may improve future efforts in treating these diseases.

\section{Acknowledgments}

K.P., J.D.M., and J.E.J. are supported by National Cancer Institute Specialized Programs of Research Excellence (SPORE) in Lung Cancer P50CA70907 and UO1CA213338.

\section{References}

Borromeo MD, Savage TK, Kollipara RK, He M, Augustyn A, Osborne JK, Girard L, Minna JD, Gazdar AF, Cobb MH, et al. 2016. ASCL1 and NEUROD1 reveal heterogeneity in pulmonary neuroendocrine tumors and regulate distinct genetic programs. Cell Rep 16: 1259-1272.

Chiappori AA, Otterson GA, Dowlati A, Traynor AM, Horn L, Owonikoko TK, Ross HJ, Hann CL, Abu Hejleh T, Nieva J, et al. 2016. A randomized phase II study of linsitinib (OSI906) versus topotecan in patients with relapsed small-cell lung cancer. Oncologist 21: 1163-1164.

Gazdar AF, Bunn PA, Minna JD. 2017. Small-cell lung cancer: what we know, what we need to know and the path forward. Nat Rev Cancer 17: 725-737.

George J, Lim JS, Jang SJ, Cun Y, Ozretic L, Kong G, Leenders F, Lu X, Fernandez-Cuesta L, Bosco G, et al. 2015. Comprehensive genomic profiles of small cell lung cancer. Nature 524: 47-53.

Huang Y-H, Klingbeil O, He X-Y, Wu XS, Arun G, Lu B, Somerville TDD, Milazzo JP, Wilkinson JE, Demerdash OE, et al. 2018. POU2F3 is a master regulator of a tuft cell-like variant of small cell lung cancer. Genes Dev (this issue). doi: 10.1101/gad.314815.118.

Mollaoglu G, Guthrie MR, Bohm S, Bragelmann J, Can I, Ballieu PM, Marx A, George J, Heinen C, Chalishazar MD, et al. 2017. MYC drives progression of small cell lung cancer to a variant neuroendocrine subtype with vulnerability to aurora kinase inhibition. Cancer Cell 31: 270-285.

Niederst MJ, Sequist LV, Poirier JT, Mermel CH, Lockerman EL, Garcia AR, Katayama R, Costa C, Ross KN, Moran T, et al. 2015. RB loss in resistant EGFR mutant lung adenocarcinomas that transform to small-cell lung cancer. Nat Commun 6: 6377 .

Osborne JK, Larsen JE, Shields MD, Gonzales JX, Shames DS, Sato M, Kulkarni A, Wistuba II, Girard L, Minna JD, et al. 2013. NeuroD1 regulates survival and migration of neuroendocrine lung carcinomas via signaling molecules TrkB and NCAM. Proc Natl Acad Sci 110: 6524-6529.

Saunders LR, Bankovich AJ, Anderson WC, Aujay MA, Bheddah S, Black K, Desai R, Escarpe PA, Hampl J, Laysang A, et al. 2015. A DLL3-targeted antibody-drug conjugate eradicates high-grade pulmonary neuroendocrine tumor-initiating cells in vivo. Sci Transl Med 7: 302ra136.

Yamashita J, Ohmoto M, Yamaguchi T, Matsumoto I, Hirota J. 2017. Skn-1a/Pou2f3 functions as a master regulator to generate Trpm5-expressing chemosensory cells in mice. PLoS One 12: $\mathrm{e} 0189340$.

Zhang W, Girard L, Zhang YA, Haruki T, Papari-Zareei M, Stastny V, Ghayee HK, Pacak K, Oliver TG, Minna JD, et al. 2018. Small cell lung cancer tumors and preclinical models display heterogeneity of neuroendocrine phenotypes. Transl Lung Cancer Res 7: 32-49. 


\section{CORRIGENDUM}

Genes \& Development 32: 865-867 (2018)

\section{Corrigendum: Identifying a missing lineage driver in a subset of lung neuroendocrine tumors}

Karine Pozo, John D. Minna, and Jane E. Johnson

In the above-mentioned Outlook article, there was an error in Figure 1. INSM1 was mistakenly listed in the panel with the POU2F3 ${ }^{\text {high }}$ tumors. As is clearly reported in the primary study (Huang et al. 2018), INSM1 is notably absent in the POU2F $3^{\text {high }}$ subtype of lung neuroendocrine tumors. The corrected figure is provided below and has been corrected online.

The authors apologize for any confusion this may have caused.

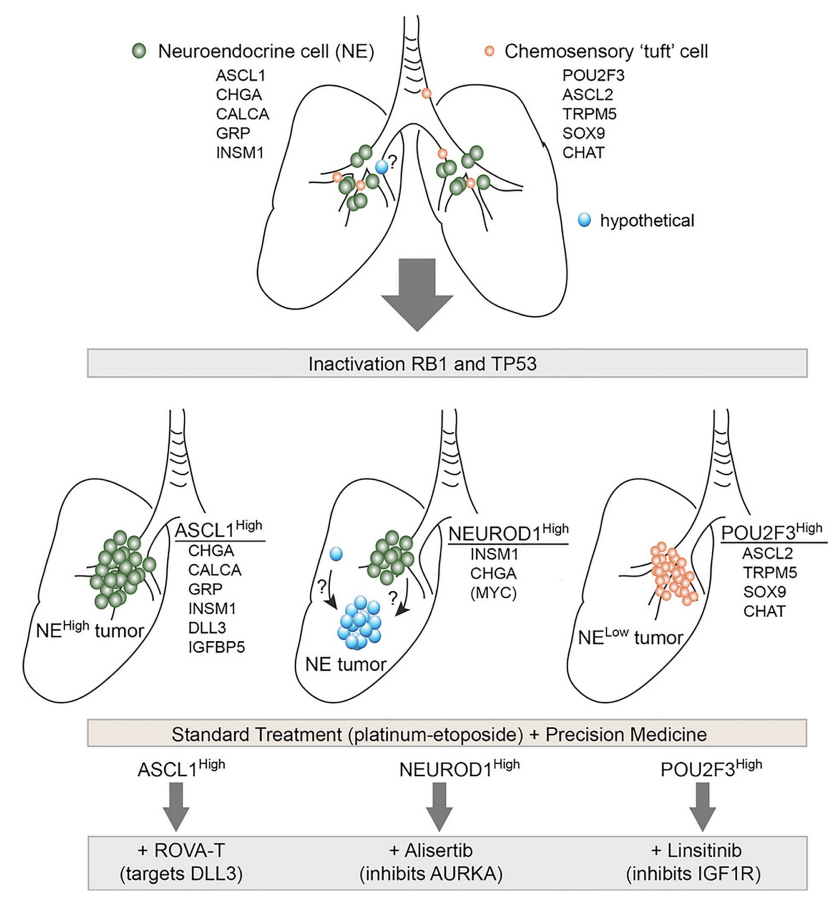

Figure 1. Heterogeneity in SCLC suggests distinct cells of origin, vulnerabilities, and responses to treatment. At least three subtypes of SCLC can be distinguished, including ASCL $1^{\text {high }}$, NEUROD $1^{\text {high }}$, and POU2F $3^{\text {high }}$, with signatures for neuroendocrine gene expression going from high to low, respectively. This heterogeneity may result from genetic inactivation of the tumor suppressors RB1 and TP53 in distinct cells in the lung, as just reported (Huang et al. 2018). Rare neuroendocrine and chemosensory cells are found in the bronchial epithelium in the adult lung that share dependency on ASCL1 (neuroendocrine cells; ASCL1 ${ }^{\text {high }}$ tumors) or POU2F3 (chemosensory tuft cells; POU2F3 ${ }^{\text {high }}$ tumors). It is not clear whether the NEUROD ${ }^{\text {high }}$ SCLCs arise from yet a different cell lineage or whether they reflect an ASCL $1^{\text {high }}$ tumor that has acquired additional genetic alterations such as MYC amplification. Nevertheless, the distinct chromatin landscape and gene expression seen in these different SCLC subtypes suggest that they will have distinct vulnerabilities and should inform precision medicine strategies (Saunders et al. 2015; Mollaoglu et al. 2017; Huang et al. 2018). 


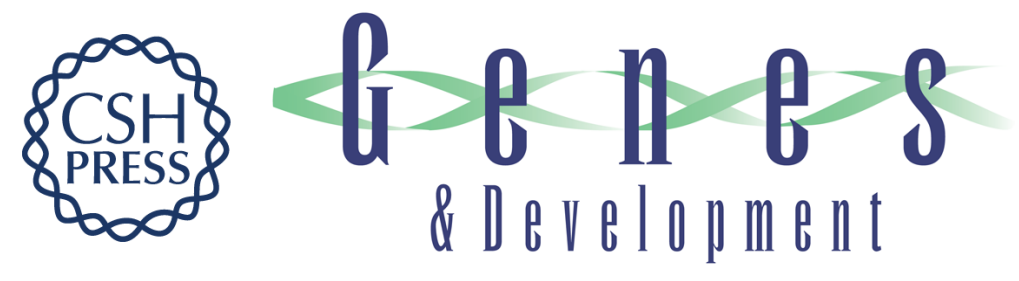

\title{
Identifying a missing lineage driver in a subset of lung neuroendocrine tumors
}

\author{
Karine Pozo, John D. Minna and Jane E. Johnson
}

Genes Dev. 2018, 32:

Access the most recent version at doi:10.1101/gad.316943.118
Related Content POU2F3 is a master regulator of a tuft cell-like variant of small cell lung cancer Yu-Han Huang, Olaf Klingbeil, Xue-Yan He, et al. Genes Dev. July, 2018 32: 915-928 Corrigendum: Identifying a missing lineage driver in a subset of lung neuroendocrine tumors
Karine Pozo, John D. Minna and Jane E. Johnson
Genes Dev. September , 2018 32: 1266
References This article cites 11 articles, 4 of which can be accessed free at: http://genesdev.cshlp.org/content/32/13-14/865.full.html\#ref-list-1
Articles cited in: http://genesdev.cshlp.org/content/32/13-14/865.full.html\#related-urls
Creative This article is distributed exclusively by Cold Spring Harbor Laboratory Press for the first Commons six months after the full-issue publication date (see
License http://genesdev.cshlp.org/site/misc/terms.xhtml). After six months, it is available under a Creative Commons License (Attribution-NonCommercial 4.0 International), as described at http://creativecommons.org/licenses/by-nc/4.0/.
Email Alerting Receive free email alerts when new articles cite this article - sign up in the box at the top Service right corner of the article or click here.

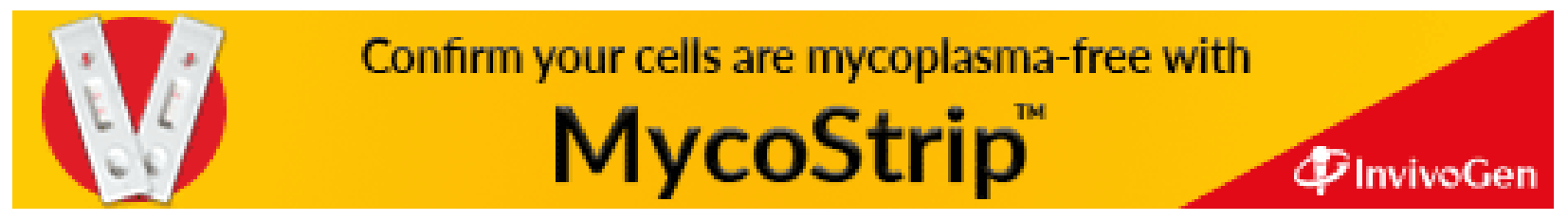

